\title{
Deformation Prediction of Soft Foundation in Airport Based on Grey Time Series Combined Model
}

\author{
Jianbo Zheng \\ School of Architecture Engineering, Binzhou University, Binzhou 256600, China
}

Keywords: grey; time series; airport; settlement prediction

\begin{abstract}
With the rapid development of China's civil aviation industry, more and more large aircrafts appear in the civil aviation industry, which puts forward new requirements for the construction of airport runway. Especially in the eastern coastal areas of China, where the soft clay layer is widely distributed, it is of great significance to fully understand and master the laws of settlement of soft ground in airport, so as to avoid unnecessary accidents. Based on the settlement monitoring data of soft foundation in an airport, in this paper the time series analysis, the grey system theory and the combination model prediction method are studied. The results show that the MGM (1,3) +AR (3) model combination can not only reflect the trend of the development and change of the sequence data, but also consider the effects of stochastic fluctuations in the data sequence, which can fit and forecast with high precision. The research results provide a reliable basis for the safety of soft foundation treatment in the construction period and operation period, and provide reference for scientific research and theoretical calculation.
\end{abstract}

\section{Introduction}

For the soft clay foundation of the airport runway, the external load is the main factor to produce the settlement after the foundation ${ }^{[1,2]}$. The external load of the field consists of two parts: the constant load of the pavement structure to the soft soil foundation and the dynamic load produced by the aircraft load on the soft clay foundation ${ }^{[3,4]}$.

Under the constant external load, with the time changing, the pore volume of soft soil foundation is reduced, and the volume of soil pores decreases. For soft clay foundation, because of slow infiltration of water in soil, the time needed to complete final settlement is very long. Sometimes it takes months, years or even decades ${ }^{[5]}$. Although the consolidation degree of soft clay foundation is about $90 \%$ after preloading, after the completion of airport, the consolidation effect of pavement structure layer on the soil will continue to exist, and the post construction settlement produced by dead load will gradually appear along with the passage of time. The current highway design criterion in China believes that the constant load of embankment is the main factor affecting the deformation of soil foundation ${ }^{[6]}$.

Because of the low permeability of soft clay foundation, the action period of aircraft landing load is relatively short, so soft clay can be regarded as undrained under the action of aircraft load ${ }^{[7]}$. Under the action of the cyclic loading of the aircraft, the soft clay foundation will produce undrained plastic cumulative strain, resulting in soil foundation settlement ${ }^{[8]}$. The researchers monitored the settlement of the soft soil foundation of an airport in Japan, and analyzed the settlement data. It was concluded that $30 \%$ of the total settlement after operation is caused by aircraft load ${ }^{[9]}$. The ground settlement of airfield runway caused by aircraft load has been paid much attention by researchers in various countries.

Time series analysis is one of the important branches of mathematical statistics and a statistical method based on dynamic data interpretation system's dynamic law and structure ${ }^{[10-14]}$. The fundamental theory can be summarized as the data recording system of the limited time. The establishment of mathematical model, which can accurately reflect the kind of dynamic time series dependency relation contained in the model can change, development trend of the future prediction system, so that the results of statistical analysis model on the causal relationship between the supplement ${ }^{[15]}$. Time series analysis method can be modeled in a stationary time series case, but in 
practice, went to the airport ground deformation monitoring data is quite complex, neither stable nor constant spacing, which is faced with the problem of pitch processing monitoring data smoothing and etc., to meet the conditions of establishing a steady time series model ${ }^{[16]}$. The grey system model is an effective method to solve the non-deterministic problem, the data is poor and the amount of information is low. After the model, the mean GM $(1,1)$ model parameters is unchanged, but the airport went to the settlement with the change of time is constantly changing, so the corresponding model parameters is bound to change, so the mean GM $(1,1)$ model applications received great limitations ${ }^{[17]}$. In view of the above reasons, a nonlinear combination of time series and grey is applied to achieve the complementary advantages of each other, reflecting the influence and development trend of the effect volume comprehensively and systematically.

\section{Modeling of time series}

The path of time series modeling and prediction is: The first step is to analyze the model order and model type, that is, which model is suitable for data sequence, including MA (q) model, AR (P) model, and ARMA (P, q) model, and determine the required order of P and Q; The second step is to estimate the variable value of the corresponding model $=($ phi 1 , Phi 2,..., [Phi] $\mathrm{P}) \mathrm{T}$ and theta $=$ (theta 1 , theta $2, \ldots$ theta q) T; the third step tests the stationary and equidistance properties of the residual epsilon T; finally, the model is predicted using the validated model [18].

In theory, all ARMA (P, q) models can be transformed into AR (P) models through reorganization and analysis. In view of the convenience and applicability, AR (P) model has wide application scope and wide range.

The model test is to test the residual sequence $\{\varepsilon(t), t \in Z\}$. If the whole development trend of the initial time series is extracted from the model, $\{\varepsilon(t), t \in Z\}$ is a stationary white noise sequence. Then it is possible to prove that the established model is applicable. On the contrary, if the residual sequence is not a stationary white noise sequence, it shows that the built model can not completely extract the change of the original data sequence. Therefore, the model should be perfected or rebuilt by various factors. [19]

For the AR (P) model, the residual is

$$
\begin{gathered}
\varepsilon_{t}=x_{t}-\hat{\varphi}_{1} x_{t-1}-\cdots-\hat{\varphi}_{p} x_{t-p} \\
\eta_{k}=\frac{\sum_{t=1}^{n-k} \hat{\varepsilon}_{t} \hat{\varepsilon}_{t-k}}{\sum_{t=1}^{n} \hat{\varepsilon}_{t}^{2}}, \quad k=1,2, \cdots, m
\end{gathered}
$$

Test statistics for constructing $\chi^{2}$

$$
\chi^{2}=n(n+2) \sum_{k=1}^{m} \frac{\eta_{k}^{2}}{n-k}
$$

Test hypothesis

$$
\begin{aligned}
& H_{0}: \rho_{K}=0, \text { if } k \geq m ; \\
& H_{0}: \rho_{K} \neq 0, \text { if } k \leq m
\end{aligned}
$$

The minimum mean square error prediction formula for AR $(\mathrm{P})$ :

$$
\hat{x}_{l+h}=\varphi_{1} x_{l+h-1}+\varphi_{2} x_{l+h-2}+\cdots+\varphi_{p} x_{l+h-p}
$$

According to the above formula, the recursive prediction formula of AR (P) can be expressed as: 


$$
\left\{\begin{array}{c}
\hat{x}_{l+1}=\varphi_{1} x_{l}+\varphi_{2} x_{l-1}+\cdots+\varphi_{p} x_{l+1-p} \\
\hat{x}_{l+2}=\varphi_{1} \hat{x}_{l+1}+\varphi_{2} x_{l}+\cdots+\varphi_{p} x_{l+1-p} \\
\vdots \\
\hat{x}_{l+h}=\varphi_{1} \hat{x}_{l+h-1}+\varphi_{2} \hat{x}_{l+h-2}+\cdots+\varphi_{p} \hat{x}_{l+h-p}(h>p)
\end{array}\right.
$$

The minimum mean square prediction formula of AR (P) model is simple and practical, The predictive value of multistep can be obtained by $x_{m}, x_{m-1}, \cdots, x_{m-p+1}$, so its applicability is better.

\section{Modeling of grey system GM $(1,1)$}

Data sequence preprocessing

The original data sequence is:

$$
X^{(0)}=\left(x^{(0)}(1), x^{(0)}(2), \cdots x^{(0)}(n)\right)
$$

Add $X^{(1)}(k)$ to a cumulative time:

$$
X^{(1)}=\left(x^{(1)}(1), x^{1}(2), \cdots x^{(1)}(n)\right)
$$

Calculating the background value of $X^{(1)}(k)$ :

$$
z^{(1)}(k)=\frac{1}{2}\left(x^{(1)}(k)+x^{(1)}(k-1)\right)
$$

The establishment of first-order differential equation

$$
\frac{d x^{(1)}}{d t}+a z^{(1)}=b
$$

Solutions of differential equations

$$
\hat{x}^{(1)}(t)=\left(x^{(0)}(1)-\frac{b}{a} e^{-a(t-1)}\right)+\frac{b}{a}
$$

The parameters a and $\mathrm{b}$ are solved by the least square method:

$$
\begin{gathered}
A=[a, b]^{T}=\left(B^{T} B\right)^{-1} B^{T} Y_{n} \\
\text { Where: } B=\left[\begin{array}{cc}
-z^{(1)}(2) & 1 \\
-z^{(1)}(3) & 1 \\
\vdots & \vdots \\
-z^{(1)}(n) & 1
\end{array}\right], \quad Y_{n}=\left[\begin{array}{c}
x^{(0)}(2) \\
x^{(0)}(3) \\
\vdots \\
x^{(0)}(n)
\end{array}\right] 。
\end{gathered}
$$

The expression of the analog predictive value is:

$$
\hat{x}^{(0)}(k)=\left(1-e^{a}\right)\left(x^{(0)}(1)-\frac{b}{a}\right) e^{-a(k-1)}, k=1,2, \cdots, n
$$

\section{Engineering application of grey time series combination model}

The phase 1 runway of Pudong International Airport was formally put into operation in October 1999. From September 2004 to September 2004, the maximum post construction settlement of the main runway has reached $611 \mathrm{~mm}$, with an average settlement of $403 \mathrm{~mm}$, which has far exceeded the design index of $100 \mathrm{~mm}$ after operation for 10 years, and the runway can still run normally. In fact, the testing indexes of the soft foundation reinforcement effect of the runway are significantly 
higher than the design requirements. The cause of this phenomenon is: First of all, in the design process of foundation treatment, settlement control after construction ignores the influence of aircraft take-off and landing load. Secondly, it is unreasonable to calculate the settlement of pavement structure under dead load after the settlement of original soft soil is subtracted from the construction period.

The settlement monitoring data of a certain point is modeled and analyzed. The results are seen in table 1, table 2 and figure 1.

Table 1 Comparison between the measured value and the fitting value of MGM $(1,3)+$ AR $(3)$ model (cm)

\begin{tabular}{|c|c|c|c|c|c|c|c|c|c|}
\hline $\begin{array}{c}\text { numbe } \\
\mathrm{r}\end{array}$ & $\begin{array}{l}\text { measure } \\
\mathrm{d} \text { value }\end{array}$ & $\begin{array}{c}\text { fitted } \\
\text { values }\end{array}$ & $\begin{array}{l}\text { residua } \\
\text { l error }\end{array}$ & $\begin{array}{c}\text { relative } \\
\text { residual } \\
\text { error(\% } \\
\text { ) }\end{array}$ & $\begin{array}{c}\text { numbe } \\
r\end{array}$ & $\begin{array}{l}\text { measure } \\
\text { d value }\end{array}$ & $\begin{array}{l}\text { fitted } \\
\text { values }\end{array}$ & $\begin{array}{l}\text { residua } \\
\text { l error }\end{array}$ & $\begin{array}{c}\text { relative } \\
\text { residual } \\
\text { error(\% } \\
\text { ) }\end{array}$ \\
\hline 1 & 10.43 & 10.67 & -0.24 & 2.27 & 16 & 191.35 & $\begin{array}{r}182.6 \\
9\end{array}$ & 8.66 & 4.52 \\
\hline 2 & 22.14 & 13.66 & 8.47 & 38.27 & 17 & 192.18 & $\begin{array}{r}196.3 \\
2\end{array}$ & -4.13 & 2.15 \\
\hline 3 & 28.72 & 25.14 & 3.58 & 12.48 & 18 & 199.30 & $\begin{array}{r}200.7 \\
5\end{array}$ & -1.45 & 0.73 \\
\hline 4 & 37.27 & 39.69 & -2.42 & 6.49 & 19 & 203.41 & $\begin{array}{r}205.0 \\
1\end{array}$ & -1.60 & 0.79 \\
\hline 5 & 45.40 & 44.69 & 0.71 & 1.56 & 20 & 217.95 & $\begin{array}{r}213.9 \\
1\end{array}$ & 4.03 & 1.85 \\
\hline 6 & 51.85 & 55.85 & -4.00 & 7.71 & 21 & 226.90 & $\begin{array}{r}228.2 \\
2\end{array}$ & -1.32 & 0.58 \\
\hline 7 & 59.92 & 63.46 & -3.54 & 5.91 & 22 & 244.48 & $\begin{array}{r}242.3 \\
9\end{array}$ & 2.09 & 0.85 \\
\hline 8 & 73.54 & 74.94 & -1.40 & 1.91 & 23 & 255.29 & $\begin{array}{r}255.2 \\
0\end{array}$ & 0.09 & 0.04 \\
\hline 9 & 90.99 & 90.28 & 0.71 & 0.78 & 24 & 262.43 & $\begin{array}{r}265.1 \\
3\end{array}$ & -2.71 & 1.03 \\
\hline 10 & 107.52 & $\begin{array}{r}108.3 \\
3\end{array}$ & -0.82 & 0.76 & 25 & 274.18 & $\begin{array}{r}268.7 \\
6\end{array}$ & 5.42 & 1.98 \\
\hline 11 & 119.49 & $\begin{array}{r}124.1 \\
3\end{array}$ & -4.64 & 3.88 & 26 & 281.09 & $\begin{array}{r}278.9 \\
4\end{array}$ & 2.15 & 0.76 \\
\hline 12 & 130.92 & $\begin{array}{r}133.9 \\
1\end{array}$ & -2.98 & 2.28 & 27 & 284.01 & $\begin{array}{r}285.1 \\
9\end{array}$ & -1.18 & 0.41 \\
\hline 13 & 145.98 & $\begin{array}{r}142.5 \\
1\end{array}$ & 3.46 & 2.37 & 28 & 286.65 & $\begin{array}{r}285.1 \\
9\end{array}$ & 1.47 & 0.51 \\
\hline 14 & 161.57 & $\begin{array}{r}156.3 \\
7\end{array}$ & 5.20 & 3.22 & 29 & 288.51 & $\begin{array}{r}289.1 \\
0\end{array}$ & -0.59 & 0.21 \\
\hline 15 & 172.86 & $\begin{array}{r}172.6 \\
2\end{array}$ & 0.24 & 0.14 & 30 & 290.40 & $\begin{array}{r}293.9 \\
2\end{array}$ & -3.52 & 1.21 \\
\hline
\end{tabular}

Table 2 The accuracy test of MGM (1,3) model and MGM (1,3) +AR (3) model (cm)

\begin{tabular}{ccccc}
\hline & \multicolumn{2}{c}{ simulation } & \multicolumn{2}{c}{ forecast } \\
\cline { 2 - 5 } & MGM(1,3) & MGM(1,3)+AR(3) & MGM(1,3) & MGM(1,3)+AR(3) \\
\hline$\sum e^{2}$ & 749.34 & 368.83 & 1097.71 & 274.40 \\
$\bar{\varepsilon}$ & 5.18 & 2.76 & 7.44 & 3.34 \\
$\bar{\Delta}$ & $4.73 \%$ & $3.59 \%$ & $5.37 \%$ & $2.78 \%$ \\
\hline
\end{tabular}




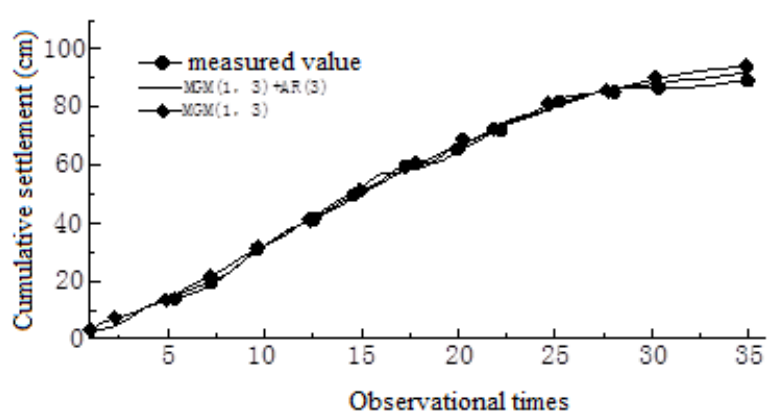

Figure1 Measured curve and fitting curves with MGM (1,3), MGM (1,3) +AR (3)

The analysis results show that the combined model can better fit the original data sequence, and can reflect the fluctuation trend of the data sequence. Compared with the MGM $(1,3)$ model, the average residual $\bar{\varepsilon}$, residual sum of squares $\sum e^{2}$ and the average relative errors $\bar{\Delta}$ of MGM $(1,3)$ +AR (3) model are significantly reduced. The fitting precision of the combined model is greatly improved. At the same time, the combination model embodies the effect of random fluctuations in the data sequence

\section{Conclusion}

In this paper, the theory of combined forecasting model is systematically expounded and analyzed. By collecting the settlement and deformation data of pile foundations, a combined model of the advantages of comprehensive single models is established, which improves the accuracy of model fitting prediction.

The weight combination model of MGM $(1,3)$ and AR (3) has the advantages of two models of grey model and time series model at the same time.It can reflect the influence of the random fluctuation of the data sequence and the trend of the change of the data sequence. These advantages and characteristics cannot be expressed in the single item model. Compared with the single model, the prediction accuracy and fitting accuracy of the combined model are significantly improved. The medium and long term prediction accuracy of the combined model is slightly lower, but the short-term prediction accuracy is high. At the same time, influenced and restricted by the single model, if the precision of the single model is low, the precision of the combined model is lower.

MGM $(1,3)+A R(3)$ combination model can consider the influence of random fluctuation of data sequence, and also can reflect the trend of development and change of data series. The accuracy of combined model prediction and fitting is higher than that of MGM $(1,3)$ model.

\section{Acknowledgment}

Research Fund Project of Binzhou University (BZXYG1620).

\section{References}

[1] Gao Liang, Jia Wei. Application of grey Verhulst-BP model in settlement analysis [J]. Geospatial Information, 2016 (08): 90-92+6.

[2] Cao Jing, Ding Wenyun, Zhao party book, Song Zhigang, Liu Haiming. Prediction of settlement time series of composite foundation based on LSSVM-ARMA model [J]. Control Engineering of China, 2016 (02): 190-196.

[3] Li Xiaogang, Zhang Ting. Application of GM $(1,1)$ grey prediction model in settlement prediction of road soft foundation [J]. Journal of Railway Science and Engineering, 2016 (01): 63-68.

[4] Lan Yang. The new airport in Xiamen reclamation area nano size Dadeng mud soft foundation treatment of construction technology [J]. China Water Transport, 2015 (08):305-306. 
[5] Guo song. Analysis and Research on monitoring data of foundation pit settlement based on time series analysis [D]. Donghua Polytechnic University, 2015.

[6] Zhang Jiafeng. Settlement analysis in the process of strengthening the soft ground of the airport runway [J]. Low Temperature Architecture Technology, 2015 (05):134-136.

[7] Wen Ming, Zhang Dingli, Fang Qian, Zhang Liang. NARXNN time series prediction model of ground surface subsidence during the construction of subway station [J]. Chinese Journal of Rock Mechanics and Engineering, 2015 (S1):3306-3312.

[8] Liu Juan.Study on long-term settlement of soft foundation of Expressway Based on measured data [D]. Southeast University, 2015.

[9] Yang Hai, Jie Daobo, Yu Qian. The method of soft foundation treatment project phase two flight zone Lukou International Airport [J]. Subgrade Engineering, 2015 (01):136-140.

[10] Cao Zhiguo. Strength characteristics of cement soil and reliability analysis of composite foundation with mixing pile [D]. Southeast University, 2015.

[11] Pang Shaowei. Analysis and prediction of soft foundation settlement in Tianjin coastal area based on Grey System [D]. China University of Geosciences (Beijing), 2014.

[12] Niu Angyi. The analysis of the stress and deformation characteristics of the foam light soil for the extension project of the expressway on the soft foundation [D]. Hebei University of Technology, 2015.

[13] Wang Liuzhun, Qiu Weining, Huang Xianghong, Jiang Jianjun. Application of wavelet time series analysis in settlement deformation of high iron [J]. Journal of Geomatics, 2013(04): $45-47+51$.

[14] Wang Ruiying, Wang Qing, Zhang Ying, Xiang Liangjun. Study on settlement prediction based on time series dynamic neural network [J]. Journal of Engineering Geology, 2013(03):351-356.

[15] Xu Aigong, Li Na, Zhang Tao. Application of time series analysis in subway settlement observation [J]. Science of Surveying and Mapping, 2013(05):57-60.

[16] Wu Shaozhu, Wu Weilin. Application of grey theory to the settlement prediction of soft foundation [J]. Henan Water Resources \& South-to-North Water Diversion, 2013(04):29-30.

[17] Zhang Longyun, Zhang Qiangyong, Yang Shangyang. Application of grey variable weight fuzzy optimization model in soft foundation reinforcement [J]. Water Resources and Power, 2013(01):131-134.

[18] Wu Boyun, Du Xingwu, Ren Yang. The accuracy of grey theory model in the application of soft foundation settlement prediction [J]. Northern Communications, 2012, (12):14-17.

[19] Wu Donghui, Tian Linya, Zhang Jinhua. Application of wavelet time series in subway subsidence monitoring [J]. Science of Surveying and Mapping, 2013 (02):150-151+149. 